\title{
Contribution of spin-trapping EPR techniques for the measurement of NO production in biological systems
}

\author{
Y. Henry* and A. Guissani \\ INSERM U 350, Institut Curie (Section de Recherche), Bât. 112, Centre universitaire, 91405 Orsay, France \\ * Corresponding author: yann.henry@curie.u-psud.fr
}

\begin{abstract}
In this overview of NO spin-trapping methods, we have pointed out their main advantages over frozen solution EPR spectroscopy detection of nitrosylated metalloproteins: improved sensitivity, potential specificity and time-resolution. A few simple ideas concerning EPR methodology have been recalled. Examples of possible artefacts, sometimes unexpected, which can easily be encountered in any analytical methods have been described. New methodological developments have also been mentioned.
\end{abstract}

\section{Abbreviations}

DETC: diethyldithiocarbamate,

DMPO: 5,5-dimethyl-1-pyrroline N-oxide,

DNIC: di-nitrosyl-iron complex,

DTCS: N-(dithiocarboxy)sarcosine,

EDRF: endothelium-derived relaxing factor,

EPR, ESR: electron paramagnetic resonance; electron spin resonance,

cGMP: cyclic GMP,

$\mathrm{Hb}$ : hemoglobin,

LPS: lipopolysaccharide,

$\mathrm{Mb}$ : myoglobin,

MGD: N-methyl-D-glucamine dithiocarbamate,

MNIC: mono-nitrosyl-iron complex,

MRI: magnetic resonance imaging,

L-NA, L-NAME, L-NMMA: respectively, L-nitroarginine, L-nitroarginine methyl ester, $\mathrm{N}^{\mathrm{G}}$-monomethylarginine,

NFkB: nuclear factor kappa $\mathrm{B}$,

7-NI: 7-nitroindazole,

L-NIO: L-N ${ }^{5}$-(iminoethyl)ornithine,

iNOS: inducible isoform of NO synthase,

PBN: phenyl-tert-butylnitrone,

PEDRI: proton-electron-double-resonance imaging,

POBN: $\alpha$-(4-pyridyl-1-oxide-N-tert-butylnitrone.

\section{Introduction}

Detection of nitric oxide remains a challenge, pointing out difficult dual requirements for specificity and sensitivity.
Historically, electron paramagnetic resonance (EPR or electron spin resonance, ESR) spectroscopy has been one of the first methods used, before 1990, for NO detection responding to the specificity requirement, following the first claims in 1987 that endothelium-derived relaxing factor (EDRF) could be NO [1-7]. Several reviews have been published accounting for these developments of NO detection by EPR spectroscopy [8-13]. NO, though a stable paramagnetic gas, is not usually detectable by itself in liquid or frozen solutions by EPR spectroscopy under standard conditions (except for an ill-defined broad signal, often referred to as "matrix-bound NO"; see [12]). The electronic structure and paramagnetism of NO have been summarized, offering simple explanations derived from quantum mechanics, for this lack of detection in the absence of specific traps $[12,14]$.

The problems related to intrinsic lack of sensitivity of the conventional CW-EPR (CW for continuous wave) method remain acute; they are being overcome by Fourier-Transform and pulsed-EPR method developments recently adapted from NMR to EPR frequency bands. Furthermore recent careful and detailed analysis has shown that some claims to strict specificity in EPR detection of NO-bound metalloproteins were somewhat optimistic and that misinterpretations of EPR spectra could creep undercover [15]. We shall point to experimental constraints related to this lack of sensitivity and to some possible artefacts in the course of this review. Comparisons with other analytical methods shall also be pointed to, keeping in mind the requirements for both specificity and sensitivity. The most commonly developed are chemiluminescence, methemoglobin formation, electrochemical methods, fluorescence methods, etc. [16]. Several books on the biological effects of NO [17,18] and on analytical methods used into NO research have been published [1923], two dealing more specifically with EPR method, edited in turn by us and Ducastel and by Lukiewicz and Zweier, taking quite different viewpoints $[10,11]$.

Nitric oxide and related nitrogen oxides found in mammals and plants derive from many sources, from the various endogenous bacterial cycles, water and air pollutions, food preservation, etc., to the L-arginine/NO synthase pathway. The steady-state concentration of NO in mammals is widely variable throughout the whole body, in the respiratory tract, in blood vessels and the cardiovascular system, in the gastrointestinal tract, etc., determined by its rate of formation 
from its different local sources, L-arginine, reduction of nitrite, bacterial nitrate-reductive metabolism, etc., and by its rate of decomposition into nitrate, eliminated in urine, through irreversible oxidation reactions with oxygen-derived species and oxygenated hemoproteins. Several active storage pools exist, linked together by fluxes between organs and systems, which are based on reversible reactions with metalloenzymes, proteins ( $S$-nitrosoalbumin, $S$-nitrosohemoglobin, etc.) and free thiols ( $S$-nitrosoglutathione, $S$-nitrosocysteine, etc.) [24], and other redox reactions such as NO-nitrite oxidation-reduction $[25,26]$. Several reviews on the various origins of NO and its metabolism and breakdown have been published [12,27], particularly the excellent and recent one by Kelm [26].

\section{EPR methodology}

The principles of NO measurement using EPR are quite straightforward. The method requires an EPR spectrometer found in a specialized Biochemistry (Chemistry) or Biophysics (Physics) laboratory and the collaboration of a spectroscopist for appraisal of the methods limitations, that we shall outline in this chapter, and for correct interpretation. Experimental conditions pertaining to NO detection have been described in several book chapters (see for example references [28-33]).

EPR is an absorption spectroscopy in the microwave frequency range, the most familiar being between 9 to $9.6 \mathrm{GHz}$ (wavelength around $3 \mathrm{~cm}$ ). In the Zeeman effect a paramagnetic sample subjected to an external magnetic field $\mathrm{H}_{0}$ sees all its energy levels, originally degenerated (having the same energy) for the electron spin quantum number, splitted into sublevels. Microwave photon absorption between these states give rise to EPR. $\mathrm{H}_{0}$ is measured in tesla, although some EPR spectroscopists continue to use the magnetic field expressed in gauss instead of the magnetic induction in tesla (10 G equals $1 \mathrm{mT})$. The resonance condition, corresponding to the photon $(h v)$ resonant absorption, is expressed by the following relationship between the microwave frequency $v$ and the magnetic field $\mathrm{H}_{0}$ :

$\Delta \mathrm{E}=h \mathrm{v}=\mathrm{g} \beta \mathrm{H}_{\mathrm{o}}$, in which $\beta$, the Bohr magneton, is a physical constant of the electron related to its charge and mass, the velocity of light and the Planck constant $h$. Operating at a standard frequency in the 9-10 GHz range (X-band), fixed by conditions imposed by the sample and the EPR cavity material (quartz, gilded waveguide and cavity, etc.) quality and geometry, a scan over a magnetic field range centered around 330-350 $\mathrm{mT}$ (that of an electromagnet) is necessary to obtain the resonance absorption. In fact, for reasons unnecessary to explain here, one obtains the derivative of a gaussian-shaped absorption versus the magnetic field [28-33]. This resonant absorption is characterized by the dimensionless constant called $g$-factor, equal to 2.0023 for a "free" electron. This $g$-factor is in fact a tensor, resolved into components indicative of the paramagnetic center spin state and symmetry: two components, $g \perp$ and $g_{/ /}$, or three $g_{x}, g_{y}$, and $g_{z}$, respectively for axial and rhombic symmetry. While radical species have resonances close to this free-electron $g$-value, transition metal complexes found in metalloproteins have $g$-values between 0.6 and 10 (see [31] for a simple review).

EPR spectra often present typical fine structures when the electron magnetic moment interacts with magnetic moments of neighboring nuclei, metal (hyperfine structure) and close ligands atoms (superhyperfine), characterized by a quantum number $I$ different from zero. It is the case for ${ }^{1} \mathrm{H}(I=1 / 2)$, ${ }^{14} \mathrm{~N}(I=1),{ }^{15} \mathrm{~N}(I=1 / 2),{ }^{57} \mathrm{Fe}(I=1 / 2)$, natural abundance ${ }^{63,65} \mathrm{Cu}(I=3 / 2),{ }^{55} \mathrm{Mn}(I=5 / 2)$, but not for natural abundance ${ }^{12} \mathrm{C},{ }^{16} \mathrm{O},{ }^{56} \mathrm{Fe}$ nuclei $(I=0)$. For instance, the $N$ nucleus of ${ }^{14} \mathrm{NO}$ gives rise to a triplet signal [13,34-38]. In the example of nitrosyl-hemoglobin $\mathrm{Hb}\left(\mathrm{Fe}^{\mathrm{II}}\right) \mathrm{NO}$, this triplet can split further to nine lines due to the proximal histidine ${ }^{14} \mathrm{~N}$ atom, ligand to the heme iron in trans position to $\mathrm{NO}$ $[8,36,37]$. The field separations between hyperfine lines are measured as A-tensor components characteristic of a nucleus and of the complex in which the nucleus participates as a metal or as one of its ligands [31]. In the instance of the complex $\mathrm{Fe}^{\mathrm{I}}(\mathrm{SR})_{2}(\mathrm{NO})_{2}$, so-called dinitrosyl-iron complex (DNIC), no hyperfine structure of ${ }^{14} \mathrm{NO}$ is resolved in EPR spectra at $77 \mathrm{~K}$, yet substitution of ${ }^{15} \mathrm{~N}$ for ${ }^{14} \mathrm{~N}$ causes line shape and line-width modifications [13,38].

Due to dielectric loss problems, particularly in liquid water, EPR spectroscopy at X-band requires biological samples to have small thickness (less than $1 \mathrm{~mm}$ ) and therefore to be contained into a quartz flat cell (nearly capillary, with a useful sample volume of 40 to 100 microliter), oriented into the EPR cavity at room temperature, or to be frozen into cylindrical quartz tubes (often $3 \mathrm{~mm}$ diameter, with a sample volume of approximately 200 microliter). Roughly, two sets of temperature conditions can be delineated: detection of NO spin-adducts in fluid samples at room temperature or detection in frozen samples requiring low temperatures, either liquid nitrogen temperature $(77 \mathrm{~K})$ or lower temperatures for detection of some nitrosylated metalloproteins $(4-20 \mathrm{~K})$ thus requiring liquid helium.

This fact severely restricts the use of conventional X-band EPR for large biological samples or living animals. Other EPR frequencies, corresponding to other microwave-bands, are only accessible in specialized laboratories, such as radiofrequency band (220-350 MHz), L (0.7 to 2, typically $1.2 \mathrm{GHz}), \mathrm{S}(3.5 \mathrm{GHz}), \mathrm{Q}(35 \mathrm{GHz})$ bands, etc. Higher frequencies permit better signal resolution and therefore better understanding of the paramagnetic species structure, while lower frequencies allow to examine larger inhomogeneous objects, thus permitting in vivo imaging. For instance, L-band corresponding to long wavelengths $(15-30 \mathrm{~cm})$ requires smaller magnetic fields $(20-50 \mathrm{mT})$ and allows to operate on large samples, and is therefore adapted for EPR imaging on live small animals (see below) $[32,39,40]$. Let us recall that the large differences in the experimental setups for EPR and proton NMR experiments are directly related to the difference in the electron magnetic moment as com- 
pared to that of a proton (600-fold). The recent developments in the use of low frequencies, 220 to $350 \mathrm{MHz}$, considered as low by EPR spectroscopists, and of the highest frequencies, 700-800 MHz, by NMR spectroscopists, show that the two domains of investigation are presently overlapping. In the comparison of EPR and NMR imaging, the overlap is still narrower, around 200 to $300 \mathrm{MHz}$. EPR imaging techniques are more recent than those of NMR and have been developed for two decades for imaging of molecular oxygen and stable nitroxide radicals $[39,41]$. They are presently being adapted to NO-imaging, with a basic proviso for specificity difficult to attain [42].

\section{Metalloproteins as spontaneous targets of nitric oxide}

Nitric oxide binds to nearly all metalloproteins in at least one of their redox states ( $\mathrm{Fe}^{\mathrm{II}}$ and $\mathrm{Fe}^{\mathrm{III}}, \mathrm{Cu}^{\mathrm{I}}$ and $\mathrm{Cu}^{\mathrm{II}}$, etc.) and specifically to iron or copper-containing proteins, forming mono- and dinitrosyl complexes (MNIC and DNIC) [4347]. These reactions have usually fast binding rates and are often reversible, with dissociation rates that differ by several orders of magnitude depending on the protein and its redox state (see for instance references $[15,46])$. Some of these nitrosylated complexes are EPR detectable and are recognized as such by use of extensive EPR catalogues. Several attempts to such compilations of EPR catalogues have been made $[8,9,37,43,44]$. EPR spectra recorded on whole cell cultures and organs have originally been taken as a proof of NO synthesis and accumulation following spontaneous binding to metalloproteins, mostly under pathological conditions under which inducible NO-synthase (iNOS) pathway is stimulated $[11,44,45,48]$.

There are many examples of spontaneous NO binding to hemoglobin in circulating erythrocytes or to heart myoglobin $[11,36,37,45,48-51]$. A recent instance demonstrates the formation of methemoglobin and nitrosyl hemoglobin in blood, following the treatment of a homozygous sickle cell anemia patient with hydroxyurea [52]. The demonstration is substantiated by following the kinetics of hydroxyurea reactions with deoxygenated sickle cell hemoglobin [53]. These findings are of great importance in the development of research for the treatment of sickle cell anemia by hydroxyurea or NO inhalation (see for instance [54-58]). In another recent instance it was shown that NOX100, a NO scavenger, had long term benefits in cardiac allograft in Lewis and Wistar-Furth rats; this was well illustrated by following the EPR signal of nitrosylated myoglobin and hemoglobin in heart tissue following grafted animal treatments with cyclosporine A and NOX100 [59]. The book edited by Lukiewicz and Zweier contains many similar instances in transplant rejection and anti-tumor defense conditions [11].

Nitric oxide binds also spontaneously to [FeS]-clusterscontaining proteins $[15,60]$, forming DNIC, though the exact relevance to $\mathrm{NO}$ effects in pathophysiological situations have been questioned by some scientists [46,61]. Many reviews on that aspect of NO metabolism have appeared.

Except for NO binding to hemoglobin, myoglobin and a few hemoproteins, EPR detection in these instances cannot be generalized as a routine quantitative spin-trapping method. There are several reasons for this limitation. Metalloproteins used as a NO-trap could only be used at too small concentrations with regard to the EPR requirement of several micromolar of nitrosylated complex for any unambiguous single-scan EPR signal detection at $77 \mathrm{~K}$, that is a few-fold above the noise-drawn limit of one micromolar. Multiple-scan spectra accumulation supposes a very stable magnetic field over the time required for this accumulation, in order to make profit of the increase in signal to noise ratio, proportional to the square-root of the number of scans. EPR detection requires also sample freezing, thus forbidding accurate time resolution. Some nitrosylated metalloproteins are only observable at low temperatures around $10 \mathrm{~K}$ or below, requiring costly equipments and liquid helium. Another reason is the interference with the irreversible reaction with oxygen in biological media, which may be fast enough even at low NO concentrations, as compared to the time-scale required for EPR sampling and detection. Difficulties may also arise from the highly reactive nitrogen dioxide radical $\mathrm{NO}_{2}{ }^{-}$and $\mathrm{N}_{2} \mathrm{O}_{3}$ formed aerobically, which are not easy to assess.

\section{Spin-trapping methods}

As mentioned in the introduction, NO is not EPR-detectable by itself, though NO binds spontaneously to many intracellular metalloproteins. However, except for $\mathrm{Hb}$ and $\mathrm{Mb}$ under specific conditions, metalloproteins cannot easily be used as NO-specific spin-traps. Several methods have been developed which stabilize NO into spin-adducts [62]. Conventional nitrones and nitroso spin-traps, used for oxygen-derived radicals, are not able to form stable NO-specific adducts. Some developments of NO-specific spin-traps are underway, but are not yet routinely used $[63,64]$.

Nitric oxide readily reacts with other free radicals [14]. The reactions of NO with tyrosyl radical-containing proteins may have physiological and physiopathological consequences in the case of ribonucleotide reductase reversible inhibition and of tyrosine iminoxyl radical formation in prostaglandin $\mathrm{H}$ synthase [65-69]. For the same reasons as above, these reactions with proteic radicals cannot give rise to NO-specific spin-trapping under routine conditions.

However the reaction of $\mathrm{NO}$ with stable free radicals of the 2-pheny-4,4,5,5-tetramethylimidazoline-1-oxyl 3-oxide (PTIO) family is widely used, especially the water soluble carboxy-PTIO and carboxymethoxy-PTIO. The method is based on the one-to-one stoichiometry of the reaction between imidazolineoxyl $\mathrm{N}$-oxides and $\mathrm{NO}$, yielding the imidazoline-1-oxyl free radical (PTI) and the nitrogen dioxide radical $\mathrm{NO}_{2}{ }^{\circ}$, and finally nitrite and nitrate (see the 
reviews $[62,70])$. The apparent second-order rate constant is rather slow, $10^{4} \mathrm{M}^{-1} \mathrm{~s}^{-1}$ [70,71]. The method is extremely convenient as two stable radicals, CPTIO and CPI, can be quantified along the reaction (see for instance [72]). However when the method is used with cellular systems, questions on the stability of both radicals and on the high reactivity of $\mathrm{NO}_{2} \cdot$ and resulting $\mathrm{N}_{2} \mathrm{O}_{3}$ can be raised, with much difficulties in establishing proper control experiments. In fact CPTIO should not be used as a scavenger of NO, without controls with another scavenger such as oxyhemoglobin [73-75]. Similar experiments have been performed, using nitronyl nitroxides, and yielding imino nitroxides.

Finally the physical interaction between stable free radicals, such as fusinite, and NO and oxygen, causing linebroadening of EPR lines, has been used in test experiments but not yet routinely [62]. The main difficulty in these imaging methods is the non-specificity of the respective effects of $\mathrm{NO}$ and $\mathrm{O}_{2}$ [76].

\section{Iron-diethyldithiocarbamate complex as NO specific spin-trap}

The complex of $\mathrm{Fe}^{2+}$ and diethyldithiocarbamate (DETC), $\mathrm{Fe}^{2+}-(\mathrm{DETC})_{2}$, forms a stable ternary complex with NO, NO$\mathrm{Fe}^{2+}$ (DETC) $)_{2}$ (often called mono-nitrosyl-iron complex, MNIC), and has been widely used since its description by Vanin and colleagues [13,34,35,38]. This complex formed in cell cultures, in dissected organs or in whole animals, is detected by EPR spectroscopy both in liquid phase at room temperature and in liquid nitrogen frozen solutions [77]. Typically an animal protocol begins with the spin-trap DETC injection (400 mg/kg, intraperitonaly) simultaneously with ferrous citrate $(40 \mathrm{mg} / \mathrm{kg}$ FeSO4, $200 \mathrm{mg} / \mathrm{kg}$ sodium citrate, subcutaneously) thirty minutes before injection, inhalation or ingestion of the product (kaïnate, LPS, etc.) under study, and half an hour before animal sacrifice (see for example [78-81]). Organs dissection, for instance cerebral cortex and cerebellum, are homogenized in buffer, and immediately examined by EPR spectroscopy at room temperature or frozen into liquid nitrogen for $77 \mathrm{~K}$ EPR detection. For in vitro work with NO-donors or cell suspensions, the water insoluble $\mathrm{Fe}^{2+}$-(DETC $)_{2}$ complex is "dissolved" in yeast cell membranes [34,35].

The spectral feature of the ternary complex $\mathrm{NO}-\mathrm{Fe}^{2+}$ $(\text { DETC })_{2}$ is an axial EPR signal at $20-37{ }^{\circ} \mathrm{C}$ with $g$-values of $g \perp=2.04$ and $g_{/ /}=2.02\left(g_{\mathrm{av}}=2.03\right)$ and an easily recognized superhyperfine triplet $\left(\mathrm{A}_{14 \mathrm{~N}}=1.3 \mathrm{mT}\right)$ due to the $\mathrm{NO}{ }^{14} \mathrm{~N}$ atom at $g \perp$. A full EPR scan can be usually covered within a four-minutes period. The EPR signal can be quantified and, due to the stability of the ternary complex, the method is applicable to oxygenated organs and cell culture media. For study at $77 \mathrm{~K}$ the homogenate is extruded into a quartz EPR tube ( $3 \mathrm{~mm}$ inner diameter $)$ in a volume sufficient to exceed the EPR cavity height $(\sim 2.3 \mathrm{~cm})$, immediately frozen and kept at liquid nitrogen temperature until EPR recording. Quartet hyperfine lines of the $\mathrm{Cu}^{2+}$ $(\mathrm{DETC})_{2}$ complex (due to the $\mathrm{Cu}$ atom, $\mathrm{A}_{\mathrm{Cu}} \sim 4.9 \mathrm{mT}$ ), always found in tissues, are detected together with the triplet of the ternary $\mathrm{NO}-\mathrm{Fe}^{2+}-(\mathrm{DETC})_{2}$ complex centered at $g_{\text {av }}=2.035$. The vertical amplitude of this triplet signal, between the maximum of the peak at $g=2.047$ and the trough at $g=2.025$, is proportional to the bound NO concentration [78-83]. Depending on the nature of the tissue under study, for instance liver or spleen, EPR signals of heme-NO and [FeS]-NO arising from intrinsic protein targets of NO, can be simultaneously detected without quantitative interference $[11,84]$.

Injection of exogenous iron citrate provides a large excess of $\mathrm{Fe}^{2+}$-(DETC $)_{2}$ complex over $\mathrm{NO}$ as inferred from the $\mathrm{Cu}^{2+}-(\mathrm{DETC})_{2}$ complex EPR spectrum. Furthermore the $\mathrm{Fe}^{2+}$-(DETC $)_{2}$ trap seems to be evenly distributed throughout the body $[13,35,38]$. This method has received wide applications in animal model stress and shock pathologies, cancerology, heart and brain ischemia-reperfusion, brain diseases, autoimmune diseases, viral infections, etc., and the ternary complex can be detected in most animal organs, brain, heart, liver, spleen, kidney, lung, stomach, blood vessels, solid tumors and ascites, etc. (see for examples the following references $[11,13,71,84,85])$. A three-dimensional imaging method using an L-band bridge $(1.2 \mathrm{GHz})$ has been developed using this NO-Fe ${ }^{2+}-(\text { DETC })_{2}$ complex; NO production was detected in frozen brain of rats subjected to ischemia-hypoxia [86]. In vivo $\mathrm{NO}$ detection in the brain of septic living rats was possible with a $700 \mathrm{MHz}$ home-built EPR system [77]. Further developments of such in vivo imaging methods are described below.

\section{Other related iron-dithiocarbamate complexes}

Several other dithiocarbamate iron derivatives with high affinity for NO are commonly used. While lipid solubility of DETC complex as opposed to its water insolubility can be taken as an advantage, N-methyl-D-glucamine dithiocarbamate (MGD) has been proposed as a water soluble NO spin-trap. The ternary NO-Fe ${ }^{2+}-(\mathrm{MGD})_{2}$ complex presents the typical triplet feature very close to that of the DETC complex $\left(g_{\text {av }}=2.04 ; A_{\mathrm{N}}=1.25 \mathrm{mT}\right)$. It allowed the first real time detection of NO in a live animal over long periods of several hours, with a time scale resolution of the order of the minute $[87,88] . \mathrm{Fe}^{2+}-(\mathrm{MGD})_{2}$ was injected into the mouse tail lateral vein together with nitroprusside, used in the treatment of severe hypertension and effective as a NOdonor. The triplet signal was detected in a continuous way in the tail blood circulation of the conscious mouse at ambient temperature, by using an S-band EPR spectrometer (3.5 GHz) and a loop-gap resonator with a 4-mm loop [87]. A similar in vivo detection of NO was performed in septicshock mice, following intravenous injection of bacterial LPS and NO synthesis via the inducible L-arginine pathway [88]. The method was also tested at X-band on various systems such as macrophage and neural cell cultures stimulated by 
LPS [89], in the biliary efflux (compared to liver tissue) of LPS-treated rats [90], in rat postischemic heart, both at room temperature and on frozen tissues, using both DETC and MGD spin-traps for comparisons [91]. No cellular or organ toxicity of these spin-traps was apparent. A limit of 5 micromolar ternary complex was estimated for the EPR detection at room temperature, for a sample volume of 100 microliters [90].

This $\mathrm{Fe}^{2+}-(\mathrm{MGD})_{2}$ complex can be routinely used at room temperature and the resulting EPR signal observed directly in a flat EPR cell $[92,93]$. It gave clear-cut evidence for the production of NO from the L-arginine-NO synthase system, at a period when some controversy arose over the formation of superoxide and nitroxyl anions catalyzed by this enzyme [92]. In another instance it has been used to demonstrate the NO synthesis from cardiac muscle neuronal NO synthase isoform located on sarcoplasmic reticulum (SR) of cardiac myocytes. The spin trap MGD (5 mM) and iron (1mM) solution was infused in cardiac muscle SR vesicles directly into the EPR cell [93]. The interest of this EPR method ensues from the detection of both $\mathrm{NO}$ and oxygen radicals in the same experiments using spin-traps with different and, hopefully exclusive specificities [71,92].

Yoshimura, Fujii and others have developed dithiocarbamate derivatives expected to be even more water-soluble than MGD, such as $\mathrm{N}$-(dithiocarboxy)sarcosine (DTCS) or having substituted proline, pyrrolidine and serine moiety such as N-methyl-L-serine and L-proline-dithiocarbamate [94-98]. These spin-traps are very efficient, close to the stoichiometry, and bind NO with large rate constant, $1.1 \times 10^{8} \mathrm{M}^{-1} \mathrm{~s}^{-1}$, which represents a real advantage for selectivity and time resolution over the much slower reaction of NO with CPTIO of $10^{4} \mathrm{M}^{-1} \mathrm{~s}^{-1}[70,97]$.

\section{Possible artefacts in the use of iron-dithiocarbamate complexes in NO detection}

Many points, leading to possible drawbacks, are to be kept in mind when designing new protocols and analyzing results making use of iron-dithiocarbamate complexes, as most of them require performance of control experiments and precise timing. NO has been shown to derive in animal tissues solely from guanidino nitrogens of L-arginine and to account completely for the oxygenated nitrogen species generated from these $N$ atoms $[84,99]$. Things could be more complicated under some particular physiopathological situations, due to the existence of a substantial intermediate nitrite pool (see below).

On a long time scale, hours to days, DETC injection can by itself induce artefacts. DETC acts as a superoxide dismutase inhibitor in mice and given as a prolonged treatment 4 days before ischemia, it has, as a result, significant protective effects against cerebral ischemia [100,101]. DETC, like other dithiocarbamates, inhibits induction of macrophage NO synthase [102]. Another dithiocarbamate derivative, pyrrolidine dithiocarbamate has been used to demonstrate how neuronal NOS regulates nuclear factor kappaB (NFkB) activity and iNOS expression [103]. It is an inhibitor of $\mathrm{NFKB}$ in most cells and is also a scavenger of NO through formation of MNIC. By comparing EPR signals of $\mathrm{NO}-\mathrm{Fe}^{2+}-(\mathrm{DETC})_{2}$ complex in liver tissue to those of $\mathrm{HbNO}$ in whole blood of the same LPS-treated mice, it was found that exogenous iron administration attenuates NO level and iNOS expression [104]. Some contradictory reports also appeared on the roles of exogenous iron in dithiocarbamates NO scavenging. While iron-citrate administration was found to potentiate bacterial LPS-induced NO production in most organs of treated mice [105], the increase of the $\mathrm{NO}-\mathrm{Fe}^{2+}-(\mathrm{DETC})_{2}$ complex EPR signal induced by iron administration was correlated to an enhancement of the DETC spin-trapping ability [106]. These differences in analysis could also be related to uneven distribution of NO synthesis in organs as well as in circulating blood. The method has recently pointed out that halothane anesthesia itself could interfere with NO content in rat brain in a time dependent manner, through complex modifications of NO synthases activity [107].

\section{Other possible interferences with nitrite, NOS inhibitors and exogenous agents}

Extremely fine experiments clearly demonstrated that there could exist massive formation of NO, derived from nitrite $[25,108]$. While NO was found to be derived from the NO/L-arginine system catalysed by NO synthases, both by use of the exogenous Fe-MGD complex and by the EPR spectra of heme-NO complex in heart tissue subjected to prolonged $(8 \mathrm{~h})$ ischemia, a large proportion of these two accumulated complexes could not be suppressed by treatment with L-NAME, a potent inhibitor of NOS enzymes. Careful experiments and analysis showed firstly that a large pool of nitrite $(12 \pm 5$ micromolar over a series of five hearts, measured by a Sievers NO analyser following nitrite reduction by acidic $\mathrm{KI}$ ) existed in heart tissue prior to the onset of ischemia. Secondly the myocardial $\mathrm{pH}$ (measured in vivo by ${ }^{32} \mathrm{P} \mathrm{NMR}$ ) decreased from 7.1 to 5.5 (with a threshold $\mathrm{pH}$ value near 6.0) after 25 minutes of provoked ischemia. Thirdly using ${ }^{15} \mathrm{~N}$ substitution to ${ }^{14} \mathrm{~N}$ nitrite, nitrite was demonstrated to be the chemical source of this acidic formation of NO. This enzyme-independant formation of NO could result from nitrite reduction by large reductive pools and from its disproportionation into nitrate and NO, occurring from the myocardial acidosis following ischemia [108]. Similar acidic conditions probably occur normally in the stomach and in the mouth [25]. A few control experiments showed that a possible involvement of cytochrome $c$ oxidase seemed improbable [109]. By use of concurrent estimates of NO by EPR spin-trapping and chemiluminescence, the same group proposed a complete model of NO production from nitrite, evaluating magnitude and rates of nitrite disproportionation versus $\mathrm{pH}$ value, and stressing that the 
rate of nitrite conversion was too slow to be measured at physiological $\mathrm{pH}$ values [110].

Simultaneously some doubt was raised on the possibility of reduction of accumulated nitrite to NO by exogenous iron citrate, even at physiological pH [111]. EPR spectroscopy of the same system, together with a commercial NO-specific electrode, were used to investigate whether NO formation followed the reduction of nitrite by $\mathrm{Fe}^{2+}-(\mathrm{MGD})_{2}$ under anaerobic conditions [112]. In fact the rate of the EPRdetectable NO-Fe ${ }^{2+}-(\mathrm{MGD})_{2}$ complex was demonstrated to be a function of the squared concentration of ferrous iron, and of MGD, nitrite and proton concentrations. The existence of this nitrite reduction reaction could artificially extend the observed time course in the detection of L-arginine-derived NO and, whenever diet is the source of nitrite, it could lead to gross misinterpretations of biological phenomena [112].

Using the good specificity of Fe-MGD complex for NO trapping, it was demonstrated that NO could be generated from well known oxygen-radicals spin-trapping agents, nitrones and $\mathrm{N}$-oxides (PBN, POBN, DMPO) when these compounds were UV-irradiated in the presence of oxygen and Fenton reagents (iron or copper sulfate $160 \mathrm{mM}$, hydrogen peroxide $3 \mathrm{mM}$ ) [113]. NO formed under such drastic a way was assayed by cGMP radioimmunoassay. This finding explained the vasodilator activity of these spin-traps and some of their effects when injected in vivo for imaging experiments.

Two other unexpected effects, deriving from typical "control" experiments, were related to NO production from the L-arginine/NO synthase pathway. Guanidino-substituted L-arginine analogs (L-NA, L-NAME, L-NMMA, L-NIO) are competitive inhibitors of NOS and are used in high doses to compete with millimolar L-arginine intracellular concentrations [114]. Spin-trapping by the Fe-MGD complex demonstrated a non-enzymatic production of NO, at micromolar levels, from these NOS inhibitors by reducers like ascorbate and NADPH, and to a lesser extent thiols, glutathione, L-cysteine and dithiothreitol [114]. For instance the reaction of an equimolar mixture $(25 \mathrm{mM})$ of L-NA and ascorbate would yield as high as a 100 micromolar concentration of NO. Such a synthesis of NO can produce in vivo potentially toxic levels of NO opposed to the effects of NOS inhibition [114]. Similar reduction of nitroaromatic compounds, such as 7-nitroindazole (7-NI), a specific inhibitor of neuronal NOS, could occur particularly under hypoxic conditions, under which the futile reaction with superoxide anion could not substantially occur.

Another recent report brought the apparently contradictory new result of a reaction of Fe-DTCS or Fe-MGD complex with neuronal NOS leading to its in vitro inhibition, with respective $\mathrm{IC}_{50}$ of 10 and 25 micromolar [115]. The mechanism underlying this reversible non-competitive inhibition is not fully understood, though interference with the electron flow from HADPH to heme could be suggested. This inhibition, independently of the effect of thiocarbamates on NOS expression, would lead to an underestimation of NO synthesis in imaging experiments in vivo.

\section{Three-dimensional EPR imaging and other recent methodological developments}

Several research groups have adapted spin-trapping methods based on iron-thiocarbamate complexes to NO-imaging of small laboratory animals such as rats or mice. By use of the Fe-DTCS complex synthesized by Satoshi Fujii and colleagues [94,95], Yoshimura and colleagues could trap, stabilize and accumulate the nitrosylated ternary complex detected at $700 \mathrm{MHz}$, in the abdomen, particularly the liver, of LPS-treated mice and make a tomographical description of three-dimensional images [96]. The method was fully described and generalized with other spin-traps [116,117]. Similar experiments, using Fe-MGD and a microwave frequency of $1.2 \mathrm{GHz}$, were simultaneously described by Zweier's group in rat brains subjected to ischemia-reperfusion or in ischemic rat hearts $[40,86,118]$. Finally a third group attempted to quantitate $\mathrm{NO}$ by ex vivo and in vivo experiments in several regions of mice brain making use of $\mathrm{X}$ and L-bands [119,120]. These experiments are promising attempts at NO-specific imaging but have not yet received any applications in experimental physiopathology.

The paramagnetic ternary $\mathrm{NO}-\mathrm{Fe}^{2+}-(\mathrm{MGD})_{2}$ complex has been tested to use as a magnetic resonance imaging (MRI) contrast agent [121]. This complex appeared as more stable in vivo and a more effective MRI contrast agent than other stable N-containing free radicals [121]. A similar approach was recently attempted by proton-electron-double-resonance imaging (PEDRI), making use of the nitroprusside-derived radical, the DNIC of NO with the iron-serum albumin complex and the MNIC with MGD [122]. A new non-invasive imaging method could be derived.

\section{Conclusion}

In this critical if not exhaustive review of NO spin-trapping methods, we have pointed out their main advantages and intrinsic defect: good potential specificity, reasonable timeresolution as opposed to poor sensitivity. The need of control experiments, trivial as in any other analytical method, has revealed many possible reactions of exogenous NO spintrapping agents, too often overseen in similar oxygenderived radicals spin-trapping experiments. Several instances have been given showing the necessary use of at least two different EPR probes or two different analytical methods to arrive at sound conclusions.

\section{Acknowledgements}

This work has been supported by grants from Institut National de la Santé et de la Recherche Médicale and from Institut Curie (Section de Recherche) to our laboratory. 


\section{References}

1. Vanhoutte, P. M. The end of the quest? Nature 1987, 327, 459460.

2. Greenberg, S. S.; Wilcox, D. E.; Rubanyi, G. M. Endotheliumderived relaxing factor released from canine femoral artery by acetylcholine cannot be identified as free nitric oxide by electron paramagnetic resonance spectroscopy. Circ. Res. 1990, 67, 1446-1452.

3. Wennmalm, A.; Lanne, B.; Petersson, A.-S. Detection of endothelium-derived factor in human plasma in the basal state and following ischemia using electron paramagnetic resonance spectrometry. Anal. Biochem. 1990, 187, 359-363.

4. Pellat, C.; Henry, Y.; Drapier, J.-C. IFN- $\gamma$-activated macrophages : detection by electron paramagnetic resonance of complexes between L-arginine-derived nitric oxide and nonheme iron proteins. Biochem. Biophys. Res. Commun. 1990, 166, 119-125.

5. Lancaster, J. R., Jr; Hibbs, J. B., Jr. EPR demonstration of iron-nitrosyl complex formation by cytotoxic activated macrophages. Proc. Natl. Acad. Sci. USA 1990, 87, 12231227.

6. Drapier, J.-C.; Pellat, C.; Henry, Y. Generation of EPRdetectable nitrosyl-iron complexes in tumor target cells cocultured with activated macrophages. J. Biol. Chem. 1991, 266, 10162-10167.

7. Henry, Y. A. The use of EPR spectroscopy for the identification of the nature of endothelium-derived relaxing factor. In: Nitric oxide research from chemistry to biology : EPR spectroscopy of nitrosylated compounds; Henry, Y. A.; Guissani, A.; Ducastel, B., Eds, Austin, Texas, USA: Landes, RG 1997, pp 193-204.

8. Henry, Y.; Ducrocq, C.; Drapier, J.-C.; Servent, D.; Pellat, C.; Guissani, A. Nitric oxide, a biological effector. Electron paramagnetic resonance detection of nitrosyl-iron-protein complexes in whole cells. Eur. Biophys. J. 1991, 20, 1-15.

9. Henry, Y.; Lepoivre, M.; Drapier, J.-C.; Ducrocq, C.; Boucher, J.-L.; Guissani, A. EPR characterization of molecular targets for NO in mammalian cells and organelles. FASEB J. 1993, 7, $1124-1134$

10. Henry, Y. A.; Guissani, A.; Ducastel, B., Eds. Nitric oxide research from chemistry to biology : EPR spectroscopy of nitrosylated compounds; Austin, Texas, USA: Landes, RG, 1997, 331 pages.

11. Lukiewicz, S.; Zweier, L. J., Eds. Nitric oxide in transplant rejection and anti-tumor defense; Dordrecht, The Netherlands: Kluwer Academic Publishers 1998, 376 pages.

12. Henry, Y. A.; Guissani, A. EPR detection of nitrosylated compounds: introduction with some historical background. In: Nitric oxide in transplant rejection and anti-tumor defense; Lukiewicz, S.; Zweier, J. L., Eds, Dordrecht, The Netherlands: Kluwer Academic Publishers 1998, pp 3-35.

13. Vanin, A. F.; Kleschyov, A. L. EPR studies and biological implications of nitrosyl nonheme iron complexes. In: Nitric oxide in transplant rejection and anti-tumor defense; Lukiewicz, S.; Zweier, J. L., Eds, Dordrecht, The Netherlands: Kluwer Academic Publishers 1998, pp 49-82.

14. Henry, Y. A.; Ducastel, B.; Guissani, A. Basic chemistry of nitric oxide and related nitrogen oxides. In: Nitric oxide research from chemistry to biology : EPR spectroscopy of nitrosylated compounds; Henry, Y. A.; Guissani, A.; Ducastel, B., Eds; Austin, Texas, USA: Landes, RG 1997, pp 15-46.
15. Henry, Y.; Guissani, A. Interactions of nitric oxide with hemoproteins: roles of nitric oxide in mitochondria. Cell. Mol. Life Sci. 1999, 55, 1003-1014.

16. Archer, S. Measurement of nitric oxide in biological models. FASEB J. 1993, 7, 349-360.

17. Ignarro, L. J.; Murad, F., Eds. Nitric oxide. Biochemistry, molecular biology, and therapeutic implications. Adv. in Pharmacology 34; San Diego, USA: Academic Press 1995, 516 pages.

18. Lancaster, J., Ed. Nitric oxide. Principles and actions; San Diego, USA: Academic Press 1996, 355 pages.

19. Feelisch, M.; Stamler, J. S., Eds. Methods in nitric oxide research; Chichester, England: John Wiley \& Sons Ltd 1996, 712 pages.

20. Titheradge, M. A., Ed. Nitric oxide protocols; Totowa, NJ USA: Humana Press 1998, 324 pages.

21. Packer, L., Ed. Nitric oxide. Part A. Sources and detection of NO; NO synthase. Methods in Enzymology 268; San Diego, USA: Academic Press 1996, 555 pages.

22. Packer, L., Ed. Nitric oxide. Part B. Physiological and pathological processes. Methods in Enzymology 269; San Diego, USA: Academic Press 1996, 528 pages.

23. Packer, L., Ed. Nitric oxide. Part C. Biological and antioxidant activities. Methods in Enzymology 301. San Diego, USA Academic Press 1999, 587 pages.

24. Gaston, B. Nitric oxide and thiol groups. Biochim. Biophys. Acta 1999, 1411, 323-333.

25. Zweier, J. L.; Samouilov, A.; Kuppusamy, P. Non-enzymatic nitric oxide synthesis in biological systems. Biochim. Biophys. Acta 1999, 1411, 250-262.

26. Kelm, M. Nitric oxide metabolism and breakdown. Biochim. Biophys. Acta 1999, 1411, 273-289.

27. Henry, Y. A. Introduction: the origins of nitric oxide. In: Nitric oxide research from chemistry to biology : EPR spectroscopy of nitrosylated compounds; Henry, Y. A.; Guissani, A.; Ducastel, B., Eds; Austin, Texas, USA: Landes, RG 1997, pp 3-14.

28. Singel, D. J.; Lancaster, J. R. Electron paramagnetic resonance spectroscopy and nitric oxide biology. In: Methods in nitric oxide research; Feelisch, M.; Stamler, J. S., Eds; Chichester, England: John Wiley \& Sons Ltd 1996, pp 341-356.

29. Henry, Y. A.; Singel, D. J. Metal-nitrosyl interactions in nitric oxide biology probed by electron paramagnetic resonance spectroscopy. In: Methods in nitric oxide research; Feelisch, M.; Stamler, J.S., Eds; Chichester, England: John Wiley \& Sons Ltd 1996, pp 357-372.

30. Kalyanaraman, B. Detection of nitric oxide by electron spin resonance in chemical, photochemical, cellular, physiological, and pathophysiological systems. In: Nitric oxide. Part A. Sources and detection of NO; NO synthase. Ed. Methods in Enzymology 268, Packer, L., San Diego, USA: Academic Press 1996, pp 168-187.

31. Henry, Y. A. Basic EPR methodology. In: Nitric oxide research from chemistry to biology: EPR spectroscopy of nitrosylated compounds; Henry, Y. A.; Guissani, A.; Ducastel, B., Eds; Austin, Texas, USA: Landes, RG 1997, pp 47-60.

32. Zweier, J. L.; Kuppusamy, P. Principles of EPR spectroscopy for measurement of free radicals in biological tissues. In Nitric oxide in transplant rejection and anti-tumor defense; Lukiewicz, S.; Zweier, J. L., Eds; Dordrecht, The Netherlands: Kluwer Academic Publishers 1998, pp 37-48. 
33. Ohnishi, S. T. Measurements of NO using electron paramagnetic resonance. In: Nitric oxide protocols; Methods in molecular biology 100; Titheradge, M. A., Ed.; Totowa, NJ, USA: Humana Press 1998, pp 129-153.

34. Mordvintcev, P.; Mülsch, A.; Busse, R.; Vanin, A. On-line detection of nitric oxide formation in liquid aqueous phase by electron paramagnetic resonance spectroscopy. Anal. Biochem. 1991, 199, 142-146.

35. Mülsch, A.; Mordvintcev, P.; Vanin, A. Quantification of nitric oxide in biological samples by electron spin resonance spectroscopy. Neuroprotocols 1992, 1, 165-173.

36. Kosaka, H.; Shiga, T. Detection of nitric oxide by electron spin resonance using hemoglobin. In: Methods in nitric oxide research; Feelisch, M.; Stamler, J. S., Eds, Chichester, England: John Wiley \& Sons Ltd 1996, pp 373-381.

37. Henry, Y. A. EPR characterization of nitric oxide binding to hemoglobin. In: Nitric oxide research from chemistry to biology: EPR spectroscopy of nitrosylated compounds; Henry, Y. A.; Guissani, A.; Ducastel, B., Eds; Austin, Texas, USA: Landes, RG 1997, pp 61-86.

38. Vanin, A. F. Iron diethyldithiocarbamate as spin trap for nitric oxide detection. In: Nitric oxide. Part C. Biological and antioxidant activities; Ed. Methods in Enzymology 301, Packer, L., San Diego, USA: Academic Press 1999, pp 269279.

39. Kuppusamy, P.; Chzhan, M.; Vij, K.; Shteynbuk, M.; Lefer, D. J.; Giannella, E.; Zweier, J. L. Three-dimensional spectral-spatial EPR imaging of free radicals in the heart: a technique for imaging tissue metabolism and oxygenation. Proc. Natl. Acad. Sci. USA 1994, 91, 3388-3392.

40. Kuppusamy, P.; Zweier, J. L. EPR imaging of free radicals in biological systems. In: Nitric oxide in transplant rejection and anti-tumor defense; Lukiewicz, S.; Zweier, J. L., Eds, Dordrecht, The Netherlands: Kluwer Academic Publishers 1998, pp 109-118.

41. He, G.; Shankar, R. A.; Chzhan, M.; Samouilov, A.; Kuppusamy, P.; Zweier, J. L. Noninvasive measurement of anatomic structure and intraluminal oxygenation in the gastriointestinal tract of living mice with spatial and spectral EPR imaging. Proc. Natl. Acad. Sci. USA 1999, 96, 4586-4591.

42. Zweier, J. L.; Chzhan, M.; Samouilov, A.; Kuppusamy, P. Electron paramagnetic resonance imaging of the rat heart. Phys. Med. Biol. 1998, 43, 1823-1835.

43. Henry, Y. A. Utilization of nitric oxide as a paramagnetic probe of the molecular oxygen binding site of metalloenzymes. In: Nitric oxide research from chemistry to biology: EPR spectroscopy of nitrosylated compounds; Henry, Y. A.; Guissani, A.; Ducastel, B., Eds, Austin, Texas, USA: Landes, RG 1997, pp 99-144.

44. Henry, Y. A.; Ducastel, B.; Guissani, A. Enzymatic targets of nitric oxide as detected by EPR spectroscopy within mammalian cells. In: Nitric oxide research from chemistry to biology: EPR spectroscopy of nitrosylated compounds; Henry, Y. A.; Guissani, A.; Ducastel, B., Eds, Austin, Texas, USA: Landes, RG 1997, pp 205-234.

45. Henry, Y. A. Overproduction of nitric oxide in physiology and pathophysiology: EPR detection. In: Nitric oxide research from chemistry to biology: EPR spectroscopy of nitrosylated compounds; Henry, Y. A.; Guissani, A.; Ducastel, B., Eds; Austin, Texas, USA: Landes, RG 1997, pp 235-270.

46. Cooper, C. E. Nitric oxide and iron proteins. Biochim. Biophys. Acta 1999, 1411, 290-309.
47. Torres, J.; Wilson, M. T. The reactions of copper proteins with nitric oxide. Biochim. Biophys. Acta 1999, 1411, 310-322.

48. Henry, Y. A. Effects of nitric oxide on red blood cells. In: Nitric oxide research from chemistry to biology: EPR spectroscopy of nitrosylated compounds; Henry, Y. A.; Guissani, A.; Ducastel, B., Eds; Landes, R G: Austin, Texas, USA, 1997: pp 87-98.

49. Kumura, E.; Yoshimine, T.; Tanaka, S.; Hayakawa, T.; Shiga, T.; Kosaka, H. Nitrosyl hemoglobin production during reperfusion after focal cerebral ischemia in rats. Neurosci. Lett. 1994, 177, 165-167.

50. Kharitonov, V. G.; Bonaventura, J.; Sharma, V. S. Interactions of nitric oxide with heme proteins using UV-VIS spectroscopy. In: Methods in nitric oxide research; Feelisch, M.; Stamler, J. S., Eds; John Wiley \& Sons Ltd: Chichester, England, 1996, pp 39-45.

51. Arnold, E. V.; Bohle, D. S. Isolation and oxygenation reactions of nitrosylmyoglobins. In: Nitric oxide. Part $B$. Physiological and pathological processes; Packer, L., Ed. Methods in Enzymology 269; Academic Press: San Diego, USA, 1996, pp 41-55.

52. Glover, R. E.; Ivy, E. D.; Orringer, E. P.; Maeda, H.; Mason, R. P. Detection of nitrosyl hemoglobin in venous blood in the treatment of sickle cell anemia with hydroxyurea. Mol. Pharmacol. 1999, 55, 1006-1010.

53. Kim-Shapiro, D. B.; King, S. B.; Shields, H.; Kolibash, C. P.; Gravatt, W. L.; Ballas, S. K. The reaction of deoxy-sickle cell hemoglobin with hydroxyurea. Biochim. Biophys. Acta 1999, 1428, 381-387.

54. Kinney, T. R., Helms, R. W., O’Branski, E. E., OheneFrempong, K., Wang, W., Daeschner, C., Vichinsky, E., Redding-Lallinger, R., Gee, B., Platt, O. S. and Ware, R. E. Safety of hydroxyurea in children with sickle cell anemia: results of the HUG-KIDS study, a phase I/II trial. Blood 1999, 94, 1550-1554.

55. Ware, R. E.; Zimmerman, S. A.; Schultz, W. H. Hydroxyurea as an alternative to blood transfusions for the prevention of recurrent stroke in children with sickle cell disease. Blood 1999, 94, 3022-3026.

56. Gladwin, M. T., Schechter, A. N., Shelhamer, J. H., Pannell, L. K., Conway, D. A., Hrinczenko, B. W., Nichols, J. S., Pease-Fye, M. E., Noguchi, C. T., Rodgers, G. P. and Ognibene, F. P. Inhaled nitric oxide augments nitric oxide transport on sickle cell hemoglobin without affecting oxygen affinity. J. Clin. Invest. 1999, 104, 937-945.

57. McMahon, T. J.; Stamler, S. J. Concerted nitric oxide/oxygen delivery by hemoglobin. In: Part C. Biological and antioxidant activities; Packer, L., Ed. Methods in Enzymology 301; Academic Press: San Diego, USA, 1999, pp 99-114.

58. Kosaka, H. Nitric oxide and hemoglobin interactions in the vasculature. Biochim. Biophys. Acta 1999, 1411, 370-377.

59. Roza, A. M., Cooper, M., Pieper, G., Hilton, G., Dembny, K., Lai, C. S., Lindholm, P., Komorowski, R., Felix, C., Johnson, C. and Adams, M. NOX 100, a nitric oxide scavenger, enhances cardiac allograft survival and promotes long-term graft acceptance. Transplantation 2000, 69, 227-231.

60. Foster, M. W.; Cowan, J. A. Chemistry of nitric oxide with protein-bound iron sulfur centers. Insights on physiological reactivity. J. Amer. Chem. Soc. 1999, 121, 4093-4100.

61. Brown, G. C. Nitric oxide and mitochondrial respiration. Biochim. Biophys. Acta 1999, 1411, 351-369. 
62. Henry, Y. A. Nitric oxide-specific spin-trapping EPR methods. In: Nitric oxide research from chemistry to biology: EPR spectroscopy of nitrosylated compounds; Henry, Y. A.; Guissani, A.; Ducastel, B., Eds; Landes, R G: Austin, Texas, USA, 1997: pp 293-305.

63. Korth, H.-G.; Weber, H. Detection of nitric oxide with nitric oxide-trapping reagents. In: Methods in nitric oxide research; Feelisch, M.; Stamler, J. S., Eds; John Wiley \& Sons Ltd: Chichester, England, 1996: pp 383-391.

64. Bätz, M.; Korth, H.-G.; Meineke, P.; Sustmann, R. Fluorescence detection of nitric oxide based on cheletropic spin traps. In: Nitric oxide. Part C. Biological and antioxidant activities; Packer, L., Ed. Methods in Enzymology 301; Academic Press: San Diego, USA, 1999: pp 532-539.

65. Guittet, O.; Ducastel, B.; Salem, J. S.; Henry, Y.; Rubin, H.; Lemaire, G.; Lepoivre, M. Differential sensitivity of the tyrosyl radical of mouse ribonucleotide reductase to nitric oxide and peroxynitrite. J. Biol. Chem. 1998, 273, 22136-2214.

66. Guittet, O.; Roy, B.; Lepoivre, M. Nitric oxide : a radical molecule in quest of free radicals in proteins. Cell. Mol. Life Sci. 1999, 55, 1054-1067.

67. Guittet, O.; Decottignies, P.; Serani, L.; Henry, Y.; Le Maréchal, P.; Laprévote, O.; Lepoivre, M. Peroxynitrite-mediated nitration of the stable free radical tyrosine residue of the ribonucleotide reductase small subunit. Biochemistry 2000, 39, 4640-4648.

68. Gunther, M. R.; Hsi, L. C.; Curtis, J. F.; Gierse, J. K.; Marnett, L. J.; Eling, T. E.; Mason, R. P. Nitric oxide trapping of the tyrosyl radical of prostaglandin $\mathrm{H}$ synthase-2 leads to tyrosine iminoxyl radical and nitrotyrosine formation. J. Biol. Chem. 1997, 272, 17086-17090.

69. Goodwin, D. C.; Landino, L. M.; Marnett, L. J. Reactions of prostaglandin endoperoxide synthase with nitric oxide and peroxynitrite. Drug Metabol. Reviews 1999, 31, 273-294.

70. Akaike, T.; Maeda, H. Quantitation of nitric oxide using 2phenyl-4,4,5,5-tetramethylimidazoline-1-oxyl 3-oxide (PTIO). In: Nitric oxide. Part A. Sources and detection of NO; NO synthase; Packer, L., Ed. Methods in Enzymology 268; Academic Press: San Diego, USA, 1996: pp 211-221.

71. Akaike, T.; Noguchi, Y.; Ijiri, S.; Setoguchi, K.; Suga, M.; Zheng, Y. M.; Dietzschold, B.; Maeda, H. Pathogenesis of influenza virus-induced pneumonia: involvement of both nitric oxide and oxygen radicals. Proc. Natl. Acad. Sci. USA 1996, 93, 2448-2453.

72. Singh, R. J.; Hogg, N.; Joseph, J.; Konorev, E.; Kalyanaraman, B. The peroxynitrite generator, SIN-1, becomes a nitric oxide donor in the presence of electron acceptors. Arch. Biochem. Biophys. 1999, 361, 331-339.

73. Hooper, D. C., Bagasra, O., Marini, J. C., Zborek, A., Ohnishi, S. T., Kean, R., Champion, J. M., Sarker, A. B., Bobroski, L., Farber, J. L., Akaike, T., Maeda, H. and Koprowski, H. Prevention of experimental allergic encephalomyelitis by targeting nitric oxide and peroxynitrite: implications for the treatment of multiple sclerosis. Proc. Natl. Acad. Sci. USA 1997, 94, 2528-2533.

74. Pfeiffer, S.; Leopold, E.; Hemmens, B.; Schmidt, K.; Werner, E. R.; Mayer, B. Interference of carboxy-PTIO with nitric oxide- and peroxynitrite-mediated reactions. Free Rad. Biol. Med. 1997, 22, 787-794.

75. Margulis, A.; Sitaramayya, A. Rate of deactivation of nitric oxide-stimulated soluble guanylate cyclase: influence of nitric oxide scavengers and calcium. Biochemistry 2000, 39, 10341039.
76. Clarkson, R. B.; Norby, S. W.; Smirnov, A.; Boyer, S.; Vahidi, N.; Nims, R. W.; Wink, D. A. Direct measurement of the accumulation and mitochondrial conversion of nitric oxide within Chinese hamster ovary cells using an intracellular electron paramagnetic resonance technique. Biochim. Biophys. Acta 1995, 1243, 496-502.

77. Suzuki, Y.; Fujii, S.; Numagami, Y.; Tominaga, T.; Yoshimoto, T.; Yoshimura, T. In vivo nitric oxide detection in the septic rat brain by electron paramagnetic resonance. Free Rad. Res. 1998, 28, 293-299.

78. Sato, S.; Tominaga, T.; Ohnishi, T.; Ohnishi, S. T. ESR spintrapping study of nitric oxide formation during bilateral carotid occlusion in the rat. Biochim. Biophys. Acta 1993, 1181,195197.

79. Mikoyan, V. D.; Kubrina, L. N.; Vanin, A. Detection of the generation of nitric oxide from L-arginine in the murine brain in vivo using EPR. Biofizika 1994, 39, 915-918.

80. Mülsch, A.; Busse, R.; Mordvintcev, P.I.; Vanin, A. F.; Nielsen, E. O.; Scheel-Krüger, J.; Olesen, S.-P. Nitric oxide promotes seizure activity in kainate-treated rats. NeuroReports 1994, 5, 2325-2328.

81. Shutenko, Z.; Henry, Y.; Pinard, E.; Seylaz, J.; Potier, P.; Berthet, F.; Girard, P.; Sercombe, R. Influence of the antioxidant quercetin in vivo on the level of nitric oxide determined by electron paramagnetic resonance in rat brain during global ischemia and reperfusion. Biochem. Pharmacol. 1999, 57, 199208.

82. Sato, S.; Tominaga, T.; Ohnishi, T.; Ohnishi, S. T. Electron paramagnetic resonance study on nitric oxide production during brain focal ischemia and reperfusion in the rat. Brain Res. 1994, 647, 91-96.

83. Olesen, S.-P.; Moller, A.; Mordvintcev, P. I.; Busse, R.; Mülsch, A. Regional measurements of NO formed in vivo during brain ischemia. Acta Neurol. Scand. 1997, 95, 219-224.

84. Bune, A. J.; Shergill, J. K.; Cammack, R.; Cook, H. T. L-arginine depletion by arginase reduces nitric oxide production in endotoxic shock: an electron paramagnetic resonance study. FEBS Lett. 1995, 366, 127-130.

85. Zweier, J. L.; Wang, P.; Kuppusamy, P. Direct measurement of nitric oxide generation in the ischemic heart using electron paramagnetic resonance spectroscopy. J. Biol. Chem. 1995, 270, 304-307.

86. Kuppusamy, P.; Ohnishi, S. T.; Numagami, Y.; Ohnishi, T.; Zweier, J. L. Three-dimensional imaging of nitric oxide production in the rat brain subjected to ischemia-hypoxia. $J$. Cerebral Blood Flow Metab. 1995, 15, 899-903.

87. Komarov, A.; Mattson, D.; Jones, M. M.; Singh, P. K.; Lai, C.-S. In vivo spin trapping of nitric oxide in mice. Biochem. Biophys. Res. Commun. 1993, 195, 1191-1198.

88. Lai, C.-S.; Komarov, A. M. Spin trapping of nitric oxide produced in vivo in septic-shock mice. FEBS Lett. 1994, 345, 120-124.

89. Norby, S. W.; Weyhenmeyer, J. A.; Clarkson, R. B. Stimulation and inhibition of nitric oxide production in macrophages and neural cells as observed by spin trapping. Free Rad. Biol. Med. 1997, 22, 1-9.

90. Reinke, L. A.; Moore, D. R.; Kotake, Y. Hepatic nitric oxide formation: spin trapping detection in biliary efflux. Anal. Biochem. 1996, 243, 8-14.

91. Komarov, A. M.; Mak, I. T.; Weglicki, W. B. Iron potentiates nitric oxide scavenging by dithiocarbamates in tissue of septic shock mice. Biochim. Biophys. Acta 1997, 1361, 229-234. 
92. Xia, Y.; Zweier, J. L. Direct measurement of nitric oxide generation from nitric oxide synthase. Proc. Natl. Acad. Sci. USA 1997, 94, 12705-12710.

93. Xu, K. Y.; Huso, D. L.; Dawson, T. M.; Bredt, D. S.; Becker, L. C. Nitric oxide synthase in sarcoplasmic reticulum. Proc. Natl. Acad. Sci. USA 1999, 96, 657-662.

94. Fujii, S.; Yoshimura, T.; Kamada, H. Nitric oxide trapping efficiencies of water-soluble iron(III) complexes with dithiocarbamate derivatives. Chem. Letters 1996, 785-786.

95. Fujii, S.; Miyakoda, G.; Chihiro, M.; Yoshimura, T.; Kamada, H. Nitric oxide release from porcine aorta endothelial cells measured by electron paramagnetic resonance spectroscopy. Chem. Letters 1996, 1055-1056.

96. Yoshimura, T.; Yokoyama, H.; Fujii, S.; Takayama, F.; Oikawa, K.; Kamada, H. In vivo EPR detection and imaging of endogenous nitric oxide in lipopolysaccharide-treated mice. Nature Biotechnol. 1996, 14, 992-994.

97. Paschenko, S. V.; Khramtsov, V. V.; Skatchkov, M. P.; Plyusnin, V. F.; Bassenge, E. EPR and laser flash photolysis studies of the reaction of nitric oxide with water soluble NO trap Fe(II)-proline-dithiocarbamate complex. Biochem. Biophys. Res. Commun. 1996, 225, 577-584.

98. Nakagawa, H.; Ikota, N.; Ozawa, T.; Masumizu, T.; Kohno, M. Spin trapping for nitric oxide produced in LPS-treated mouse using various new dithiocarbamate iron complexes having substituted proline and serine moiety. Biochem. Mol. Biol. Intern. 1998, 45, 1129-1138.

99. Mülsch, A.; Vanin, A.; Mordvintcev, P.; Hauschildt, S.; Busse, R. NO accounts completely for the oxygenated nitrogen species generated by enzymatic L-arginine oxygenation. Biochem J. 1992, 288, 597-603.

100. Heikkila, R. E.; Cabbat, F. S.; Cohen, G. In vivo inhibition of superoxide dismutase in mice by diethyldithiocarbamate. $J$. Biol. Chem 1976, 251, 2182-2185.

101. Ohtsuki, T.; Matsumoto, M.; Kuwabara, K.; Kitagawa, K.; Suzuki, K.; Taniguchi, N.; Kamada, T. Influence of oxidative stress on induced tolerance to ischemia in gerbil hippocampal neurons. Brain Res. 1992, 599, 246-252.

102. Mülsch, A.; Schray-Utz, B.; Mordvintcev, P. I.; Hauschildt, S.; Busse, R. Diethyldithiocarbamate inhibits induction of macrophage NO synthase. FEBS Lett. 1993, 321, 215-218.

103. Togashi, H.; Sasaki, M.; Frohman, E.; Taira, E.; Ratan, R. R.; Dawson, T. M.; Dawson, V. L. Neuronal (type) I) nitric oxide synthase regulates nuclear factor $\mathrm{\kappa B}$ activity and immunologic (type II) nitric oxide synthase expression. Proc. Natl. Acad. Sci. USA 1997, 94, 2676-2680.

104. Komarov, A. M.; Mattson, D. L.; Mak, I. T.; Weglicki, W. B. Iron attenuates nitric oxide level and iNOS expression in endotoxin-treated mice. FEBS Lett. 1998, 424, 253-256.

105. Kubrina, L. N.; Mikoyan, V. D.; Mordvintcev, P. I.; Vanin, A. F. Iron potentiates bacterial lipopolysaccharide-induced nitric oxide formation in animal organs. Biochim. Biophys. Acta 1993, 1176, 240-244.

106. Komarov, A. M.; Kramer, J. H.; Mak, I. T.; Weglicki, W. B. EPR detection of endogenous nitric oxide in postischemic heart using lipid and aqueous-soluble dithiocarbamate-iron complexes. Mol. Cell. Biochem. 1997, 175, 91-97.

107. Sjakste, N.; Baumane, L.; Meirena, D.; Lauberte, L.; Dzintare, M.; Kalvins, I. Drastic increase in nitric oxide content in rat brain under halothane anesthesia revealed by EPR method. Biochem. Pharmacol. 1999, 58, 1955-1959.

108.Zweier J.L.; Wang P.; Samouilov A.; Kuppusamy P. Enzymeindependent formation of nitric oxide in biological tissues. Nature Medicine 1995, 1, 804-809.

109.Zweier, J. L.; Samouilov, A.; Kuppusamy, P. Enzyme independent formation of nitric oxide in tissues. In: Nitric oxide in transplant rejection and anti-tumor defense; Lukiewicz, S.; Zweier, J. L., Eds; Kluwer Academic Publishers: Dordrecht, The Netherlands, 1998: pp 83-93.

110. Samouilov, A.; Kuppusamy, P.; Zweier, J. L. Evaluation of the magnitude and rate of nitric oxide production from nitrite in biological systems. Arch. Biochem. Biophys. 1998, 357, 1-7.

111. Hiramoto, K.; Tomiyama, S.; Kikugawa, K. Appearance of electron spin resonance signals in the interaction of dithiocarbamate-Fe(II) with nitrogen dioxide and nitrite. Free Rad. Res. 1997, 27, 505-509.

112. Tsuchiya, K.; Yoshizumi, M.; Houchi, H.; Mason, R. P. Nitric oxide-forming reaction between the iron-N-methyl-D-glucamine dithiocarbamate complex and nitrite. J. Biol. Chem. 2000, 275, 1551-1556.

113. Saito, K.; Ariga, T.; Yoshioka, H. Generation of nitric oxide from spin-trapping agents under oxidative conditions. Biosci. Biotechnol. Biochem. 1998, 62, 275-279.

114. Moroz, L. L.; Norby, S. W.; Cruz, L. A.; Sweedler, J. V.; Gillette, R.; Clarkson, R. B. Non-enzymatic production of nitric oxide (NO) from NO synthase inhibitors. Biochem. Biophys. Res. Commun. 1998, 253, 571-576.

115. Yoneyama, H.; Kosaka, H.; Ohnishi, T.; Kawazoe, T.; Mizoguchi, K.; Ichikawa, Y. Reaction of neuronal nitric oxide synthase with the nitric oxide spin-trapping agent, iron complexed with N-dithiocarboxysarcosine. Eur. J. Biochem. 1999, 266, 771-777.

116. Yoshimura, T.; Yokoyama, H.; Fujii, S. Electron paramagnetic resonance detection and imaging of endogenously synthesized and exogenously supplied nitric oxide. J. Magn. Reson. Anal. 1997, 3, 125-140.

117. Fujii, S.; Suzuki, Y.; Yoshimura, T.; Kamada, H. In vivo threedimensional EPR imaging of nitric oxide production from isosorbide dinitrate in mice. Am. J. Physiol. 1998, 274, G857G862.

118. Kuppusamy, P.; Ohnishi, S. T.; Zweier, J. L. Electron paramagnetic resonance imaging of nitric oxide in tissues. In: Nitric oxide in transplant rejection and anti-tumor defense; Lukiewicz, S.; Zweier, J. L., Eds; Dordrecht, The Netherlands, Kluwer Academic Publishers, 1998, pp 119-134.

119. Fujii, H.; Berliner, L. J. Nitric oxide: prospects and perspectives of in vivo detection by L-band EPR spectroscopy. Phys. Med. Biol. 1998, 43, 1949-1956.

120. Fujii, H.; Berliner, L. J. Ex vivo EPR detection of nitric oxide in brain tissue. Magn. Reson. Med. 1999, 42, 599-602.

121. Fujii, H.; Wan, X.; Zhong, J.; Berliner, L. J. In vivo imaging of spin-trapped nitric oxide in rats with septic shock: MRI spin trapping. Magn. Reson. Med. 1999, 42, 235-239.

122. Mülsch, A.; Lurie, D. J.; Seimenis, I.; Fichtlscherer, B.; Foster, M. A. Detection of nitrosyl-iron complexes by proton-electrondouble-resonance imaging. Free Rad. Biol. Med. 1999, 27, 636-646. 